\title{
Real-Time Monitoring, Analysis and Control of Power Parameters in Residential Houses Using LabVIEW
}

\author{
Behcet Kocaman* and Yunus Yiğit
}

\begin{abstract}
Electrical energy consumed in residential has an important value in total consumption. For this reason, monitoring and control of the electricity consumed in the residential offers a significant potential for energy saving. In this study, the power parameters of the linear and nonlinear loads used in the residential have measured, analyzed and controlled in real time. Thanks to real-time monitoring, analysis and control of power parameters ensure efficient use of energy. For this, power parameters of the loads used have transferred to the computer thanks to the data acquisition card. A visual interface has been created with the software designed in the Laboratory Virtual Instrument Engineering Workbench (LabVIEW) program so that the data transferred to the computer can be monitored and controlled instantly.
\end{abstract}

Index Terms - Control, energy monitoring, energy efficiency, LabVIEW, power system analysis.

\section{INTRODUCTION}

$\mathrm{E}$ LECTRIC ENERGY demand is increasing day by day. To reduce this increasing demand, it is necessary to use energy economically and efficiently. Nowadays, studies on energy efficiency and saving are ongoing. Various systems have been developed to deliver the energy produced in the electricity generation facilities to the end consumer in an efficient and quality manner. One of these systems is the energy monitoring system. Thanks to energy monitoring systems, energy efficiency can be increased in enterprises, transmission lines, production facilities, distribution facilities and buildings. For this, it is necessary to measure energy consumption, analyze the measured data and take measures for energy efficiency and quality according to the results of

BEHCET KOCAMAN, is with Department of Electrical-Electronics Engineering University of Bitlis Eren University, Bitlis, Turkey,(e-mail: bkocaman@beu.edu.tr).

(1D) https://orcid.org/0000-0002-1432-0959

*Corresponding Author.

YUNUS YİĞİT, is with Graduated from Science Institute, Department of Electrical-Electronics Engineering University of Bitlis Eren University, Bitlis, Turkey, (e-mail: yunis4963@gmail.com).

(D) https://orcid.org/0000-0002-1991-1635

Manuscript received July 13, 2021; accepted October 26, 2021.

DOI: $10.17694 /$ bajece. 970685 this analysis [1]. In addition, energy monitoring system which is helps to monitor the stability and consumption of electrical energy is an essentiality for electricity powered buildings at the present time.

In energy monitoring systems, parameters such as current, voltage, power factor, frequency, apparent power, active power, reactive power are shown. Sometimes the current and voltage in the electrical grid can be high or low. In this case, negative results such as malfunction or distortion of electrical and electronics devices occur in businesses, residential, offices, industrial facilities. These problems create high cost and large operational problems for the user consuming electricity and all the elements on the power system [2]. To prevent these problems, real-time monitoring, analysis and control of power parameters should be reported and energy management should be planned according to the report results. Some work has been done on energy monitoring systems, analysis and control. With these studies, it has been aimed to make electrical energy better quality, more efficient, faster and lower cost.

A real-time grid energy consumption profile and an energy-sensitive grid/interface selection tool are proposed for android-based smartphones [3]. The proposed system makes use of actual package measurements and exact calculations. Thus, it reports the energy consumption levels of different grid interfaces such as Wi-Fi and cellular and facilitates the horizontal / vertical transition of devices to increase the energy efficiency. General analyzes have been made to show the accuracy of the tool proposed for this.

The presented analysis of the attitudinal and socioeconomic determinants of the willingness of residential consumers to monitor their energy consumption. In their study, they were able to demonstrate how consumers' knowledge and experience of monitoring environmental attitudes, energy use and demographics affect their desire to monitor energy consumption, both in the electricity bill and smart metering information platforms [4].

The suggested that energy monitoring systems reduce energy consumption. In particular, real-time feedback to consumers has been noted to cause a significant behavioral change in energy consumption. The energy monitoring system is crucial for emerging businesses and changing industries to effectively achieve their aims. Integrating cloud / Internet of Thing (IoT) solutions can result in remarkable energy savings and improvements [5]. 
The developed an approach to identify home appliances and classify household activities in daily life using home smart meter data. It also introduced a deep learning approach based on multi-layered, feed-forward neural grids that can identify common household electrical appliances from a typical home smart meter metering. The resulting daily life classifying activities can give an idea about the attitude of the family, which has a number of applications in the field of energy and other fields [6].

The proposed the management problem of dissimilar types of Egyptian residential loads, including daily operating performance and time shifting operation capacity, has been formulated and a new smart load management method. The proposed method represents the programming section required for load management control centers and accepts the preferred working times of consumers as input data approving maximum customer satisfaction [7].

Several study proposed real-time home energy monitoring and automation system using the Arduino microcontroller board and the LabVIEW program. The proposed study was designed to be capable of measuring different electricity parameters, determining parameters of power quality, simulating and analysing signals, recording parameters and detecting faults[8-12].

The presented a real time energy monitoring system that is cost-effective and reliable. The system can be used to analyze and evaluate the household appliance's output voltage or generated energy. A hardware device was used to collect energy data that is transferred and stored to a database via cloud-based RESTful API resources. The data obtained was then used by the mobile web application to view real-time and historical energy readings[13].

A low-cost energy monitoring system has been proposed using ZigBee wireless communication with the Arduino controller to monitor real-time electrical parameters. The ZigBee and Arduino interface technique has been used to reduce more coding in the system and to take energy meter reading with less delay time. The proposed system has been developed to save energy and to raise awareness of daily power usage for residential, commercial and industrial consumers $[14,15]$.

An experimental comparison among IoTs devices with energy gathering features using wireless technology such as ZigBee, WiFi 2.4 GHz and Long Range Wireless Area Network (LoRaWAN) in order to monitoring of agricultural proposed[16].

Application of an energy monitoring device using Arduino Nano microcontroller to measure the energy consumed by any electrical appliance presented in residential homes. Besides, designed with the ability to send measured electrical power parameters to owners via SMS when requested. Proposed device is useful for homeowners who want to monitor the energy consumption of some appliances to reduce their electricity bill. Besides, It can also be used for residential energy control [17].

A smart building real-time energy monitoring system presented. The proposed system aimed at improved safety and user awareness of energy consumption at low cost. The energy consumed can be measured instantly. In case of increased power consumption, the system can be programmed and start to turn off some unimportant appliances. With the system made using a low-cost general purpose microcontroller (Arduino), the power consumption and cost are reduced [18].

In the system where the intelligent voltage and current monitoring system technique is proposed, an arduino platform is used as a microcontroller to read the voltage and current from the sensors. With the system, the measured data is sent wirelessly in monitoring a three-phase electrical system. A new android application is used for this [19].

In literature reviews on the subject, methods that help monitor and use energy efficiently such as using android smartphones [3], using arduino microcontroller [10], DFRduino Uno [13], Using Zigbee and Arduino [15], using internet of things devices [16] are presented. In this study, real time power parameters and energy consumption are monitored. In addition, the relay and the software prepared in the LabVIEW program were used to prevent the vehicles connected to the single phase electricity grid from being damaged by excessive current / voltage. In the event that the adjustable current / voltage lower and upper limit values are exceeded with the designed system, the electricity of the relevant device is cut and controlled. Thus, damage to household appliances is prevented. In addition to monitoring the novelty of the study, power parameters and energy, the control of electrical home appliances was provided. The system we proposed; the tablet performs real-time measurement, monitoring and control with mobile applications.

The rest of the paper has structured as follows. In Section 2, material and method have explained. In other words, hardware and software features of the device prototype have described. Results and discussion have investigated in Section 3. Conclusion has evaluation in Section 4.

\section{MATERIAL AND METHOD}

The proposed system consists of experimental and software. Experimental mainly includes analog/digital input and digital output circuits, myDAQ data acquisition card, test cables and computer. MyDAQ produced by National Instruments has been used to collect and process the data. SCT-13 30A is used as current sensor. This sensor offers easy use due to its non-invasive nature. $220 \mathrm{~V}-9 \mathrm{~V}$, AC-AC adapter is used as voltage sensor. A voltage divider circuit is used to adapt the output signal of the voltage sensor to the data acquisition board. A switch is installed in the system to control current and voltage manually or automatically. In addition, a $5 \mathrm{~V}$ controlled $220 \mathrm{~V}$ relay has installed to protect the system. Fault warning system has realized with visual and audible warning. The block scheme of the experimental setup is shown in Fig. 1. 


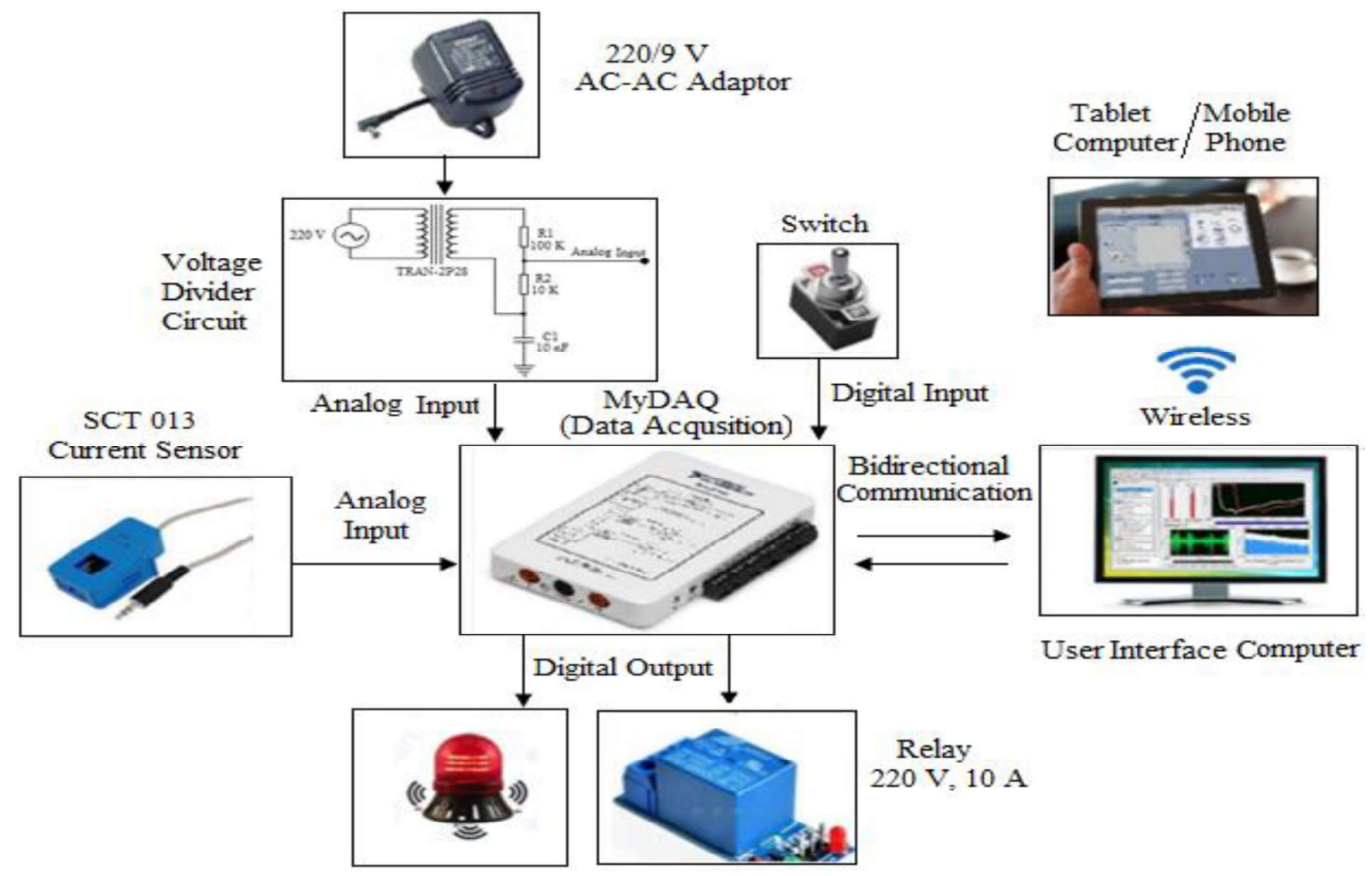

Fig. 1. Block scheme of the experimental setup.

Software is based on LabVIEW platform in computer. LabVIEW is a system-design platform and development environment for a visual programming language from National Instruments. The total cost of all components used in the proposed system was approximately $\$ 281,35$. However, devices that are used only for measuring and monitoring purposes (energy analyzer) without control feature are sold at prices of approximately \$ 1200 and above [20,21]. Data processing in LabVIEW is used to calculate and analyze the collected data. Photo of the experimental setup is shown in Fig. 2. System structure block diagram is shown in Fig. 3.

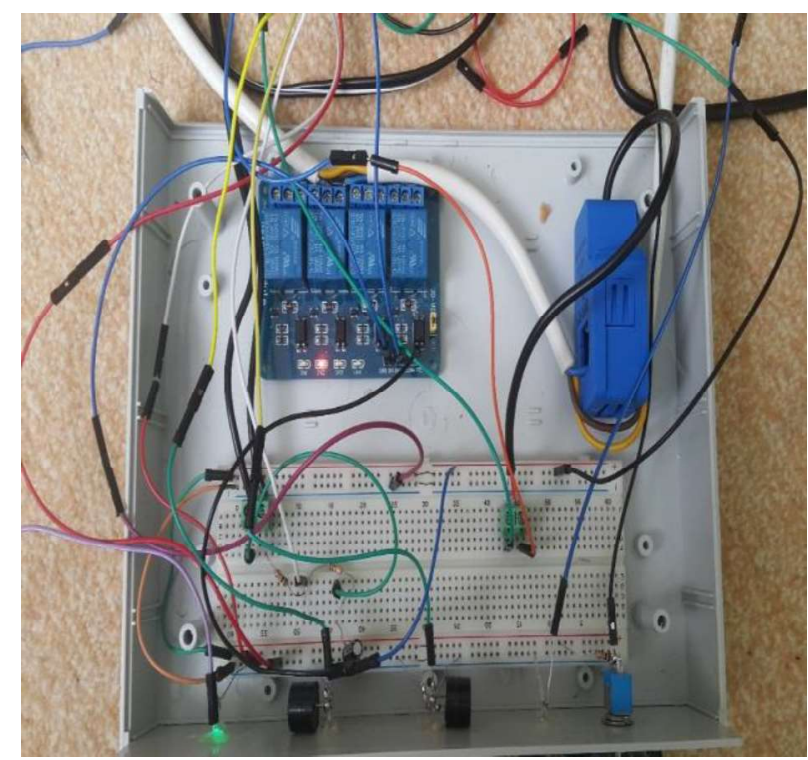

Fig. 2. Photo of the experimental setup.

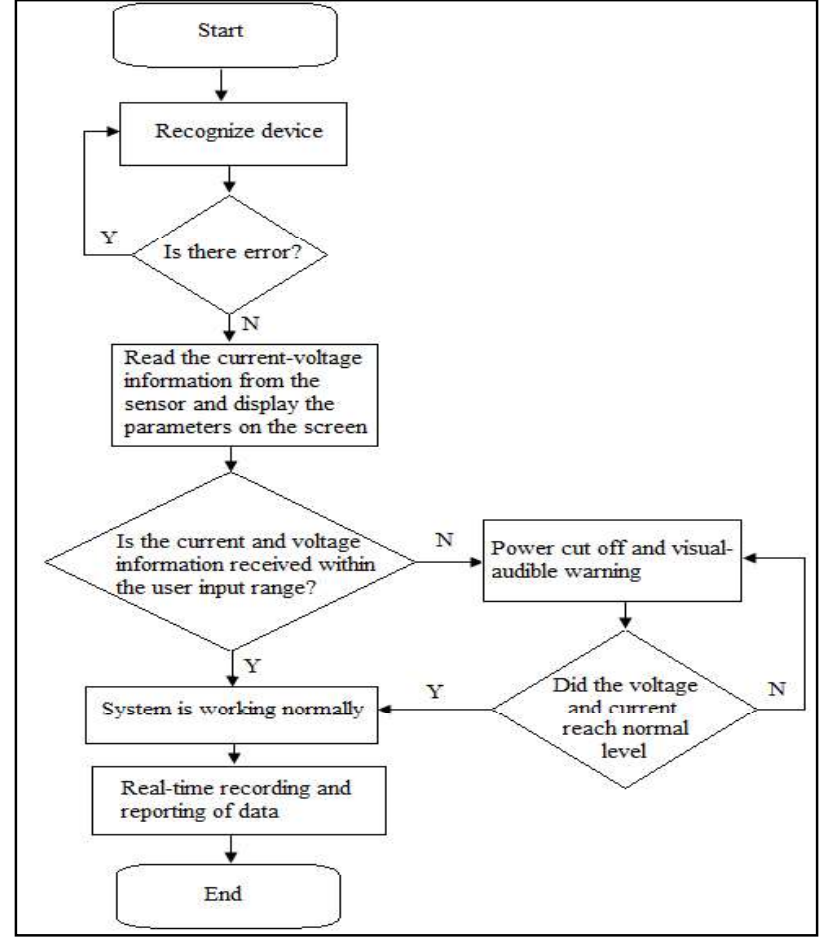

Fig. 3. System structure block diagram.

With connected linear and nonlinear loads to the system, the power parameters of the load have monitored in real time on a computer and tablet, has analyzed and controlled. The analog signal output from current and voltage sensors is integrated into the inputs of the data acquisition card. In addition, in order to monitor the data and system status, necessary designs have been made in 
the LabVIEW program and a visual interface has been created. The interface consists of two parts. In the first part, the waveform of current and voltage signals is shown on the graph. In the second part, the settings of the power parameters have been displayed numerically, system status, contact information, fault information and the recording time required for reporting parameters. The first part of the visual interface is shown in Fig. 4 and the second part is shown in Fig. 5.

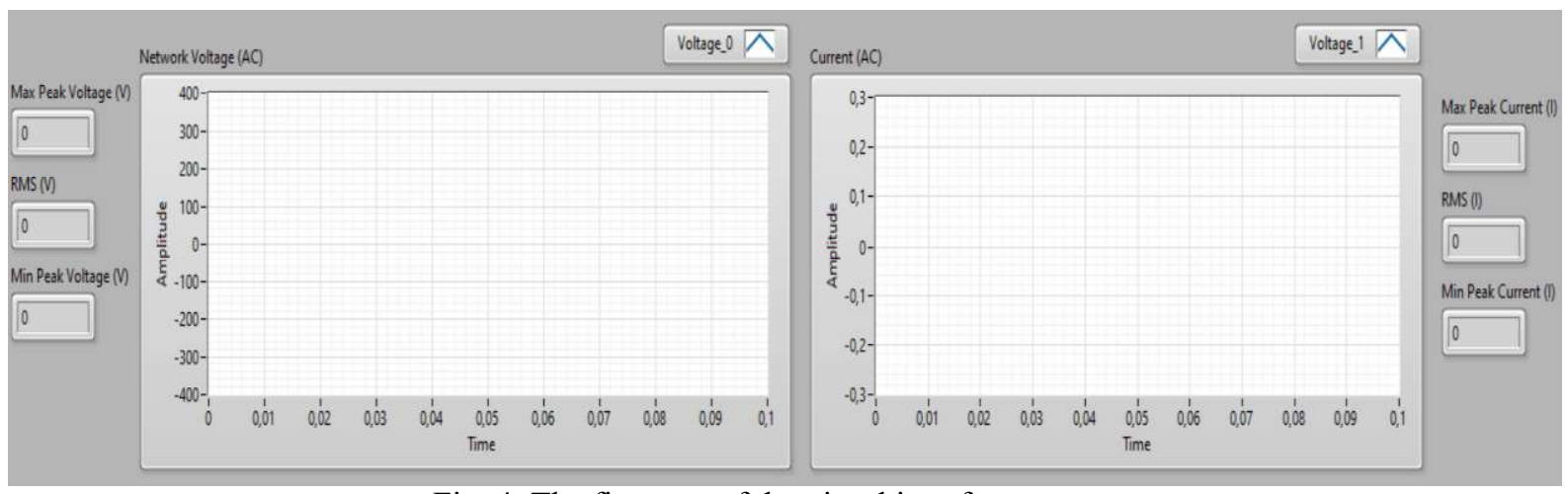

Fig. 4. The first part of the visual interface

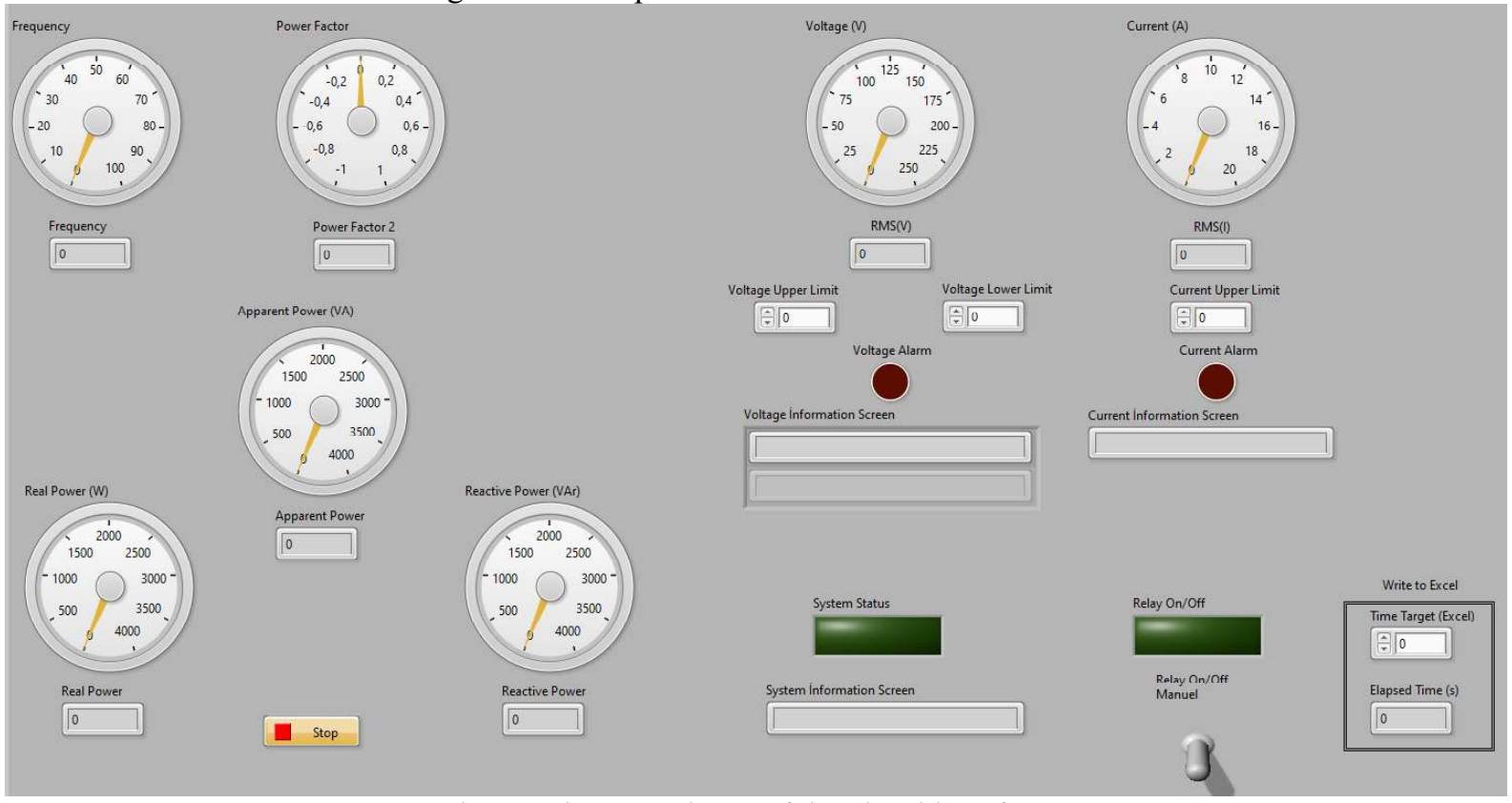

Fig. 5. The second part of the visual interface

The block diagrams used in the LabVIEW program for operating the designed system are given in Figure 6-10. The block diagram of sending alarm information to myDAQ is given in Fig. 6. The block diagram of analogue reading of the voltage signal is given in Fig. 7. An analog reading of the current signal block diagram is given in Fig. 8.

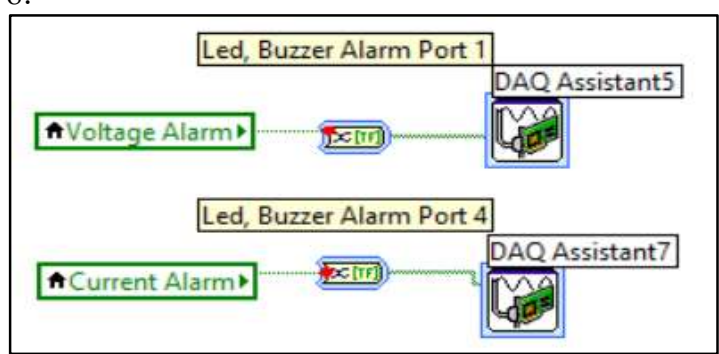

Fig. 6. Sending alarm information to myDAQ block diagram

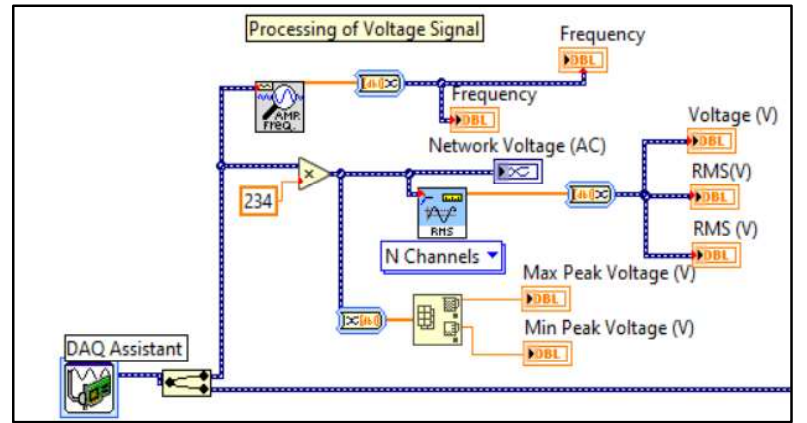

Fig. 7. Analogue reading of the voltage signal block diagram 


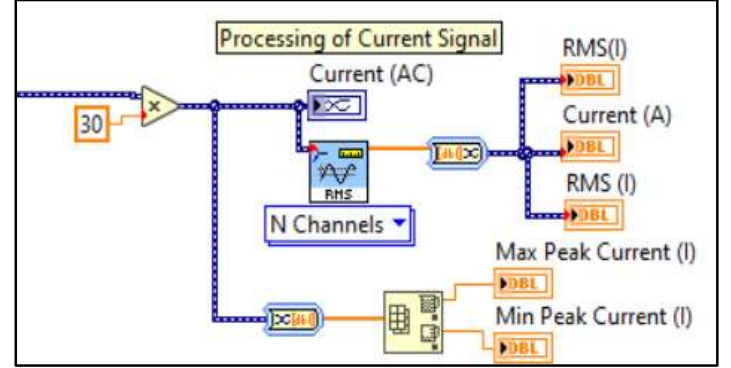

Fig. 8. Analogue reading of the current signal block diagram

Harmonic and THD analysis of the analog voltage signal received from the grid has been performed. The voltage harmonic measurement block diagram used for this is given in Fig. 9 and the current harmonic measurement block diagram in Fig. 10.

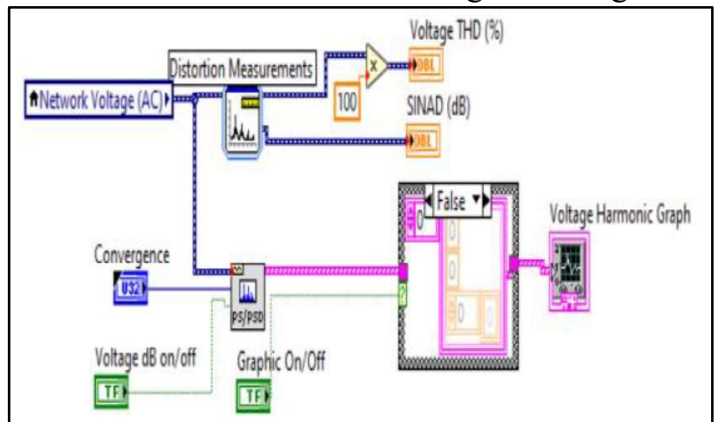

Fig. 9. Voltage harmonic measurement block diagram

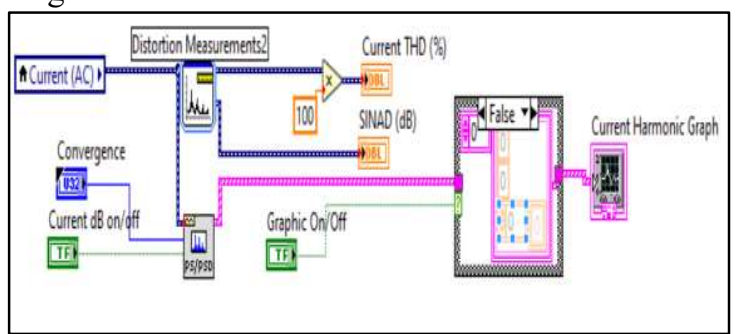

Fig. 10. Current harmonic measurement block diagram
The power parameter values taken from the data acquisition card have monitored graphically and numerically via the LabVIEW program. The data obtained are recorded by the designed system. Power parameters can be monitored within the specified time interval when wanted. In addition, according to the measured data, an automatic or manual control switch is used in order to prevent failures that may occur in the loads due to voltage drop/rise or current rise. In this way, the times when the more energy consumption of residential can be detected and electrical device failures can be prevented.

\section{RESULT AND DISCUSSION \\ The designed} system has been tested on linear and nonlinear loads. The received analog signals have been measured at a rate of 10.000 samples/second/channel and communicated with the computer. Measured analog signals were calibrated in LabVIEW program and power parameter values were monitored in computer environment. Signals created using linear and nonlinear loads have been monitored and analyzed. The proposed system has been tested by using linear and nonlinear loads separately and together. Current and voltage waveforms formed by connecting $75 \mathrm{~W}$ incandescent lamp to the system are given in Fig. 11. Also, the maximum and minimum peaks and root mean square (RMS) values of the signals have measured. Since the load is linear, the current waveform is close to the sine wave.

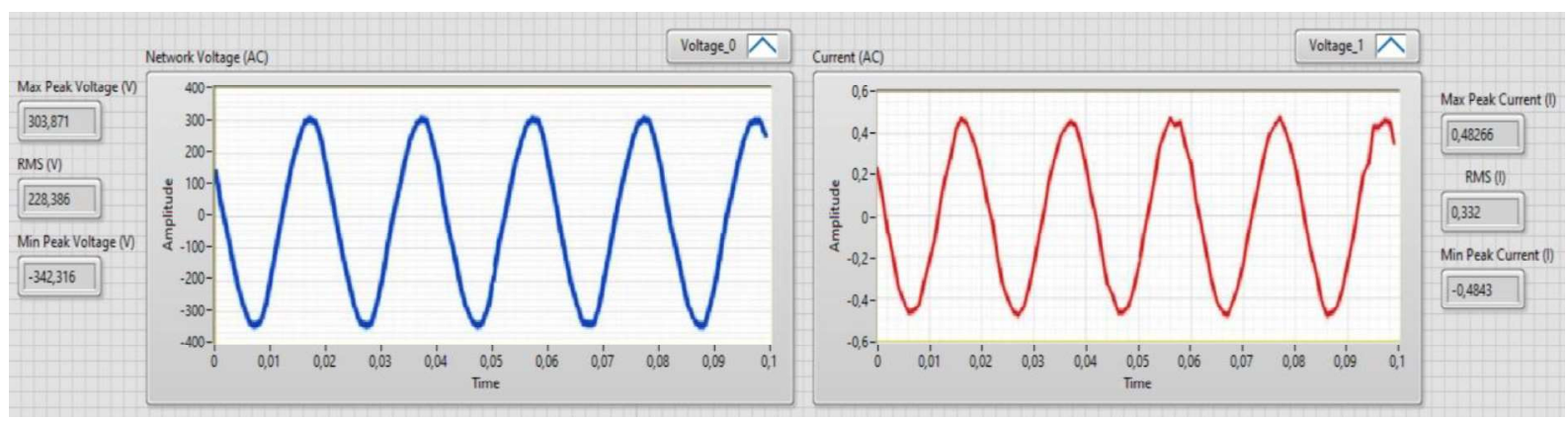

Fig. 11. 75W linear load incandescent lamp current and voltage waveforms

In case of voltage increase/drop and current increase, protection of the loads fed from single phase mains according to the limit values to be determined by the user can be done automatically or manually in this panel. Thus, electronic devices are prevented from being damaged. In Transformer Substations, relays are set to a maximum of 1-1.2 seconds [22], the opening (operation) time of the
$30 \mathrm{~mA}$ residual current protection relay which is used in residential houses is $300 \mathrm{~ms}$, and the opening time of $\mathrm{W}$ automatic fuses used in houses is $7-10 \mathrm{~ms}$ [23]. In addition, in order to inform the user, failure conditions can be seen from the voltage and current information screen of the system. Instant acquisition of power parameters is shown in Fig. 12. 


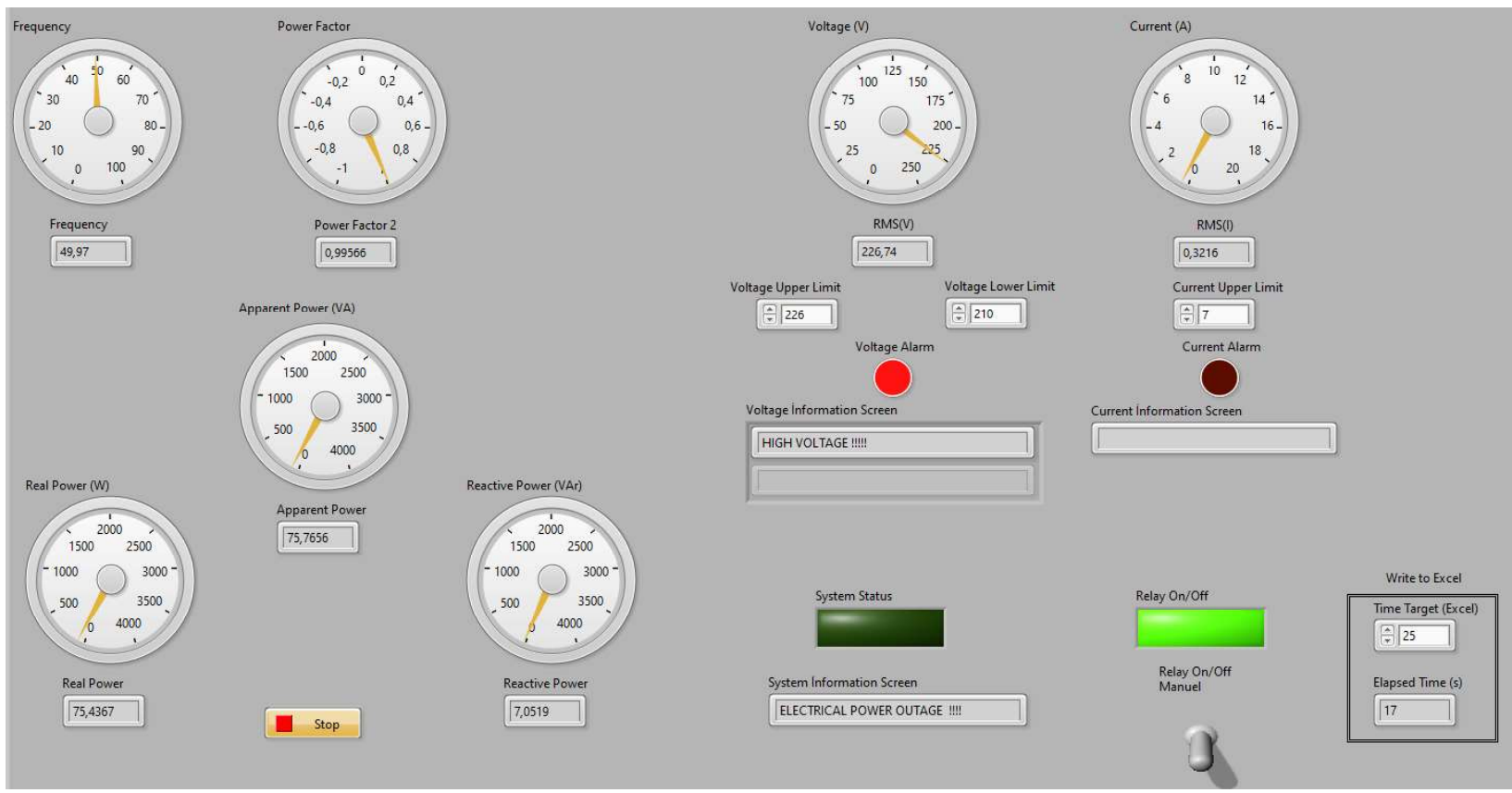

Fig. 12. System information screen and protection of devices due to voltage increase

The instantly received power parameters can record in report file in real time according to a time determined by the user. A real time report of $75 \mathrm{~W}$ incandescent lamp is given in Table 1.

TABLE I

REAL TIME REPORT OF 75 W INCANDESCENT LAMP

\begin{tabular}{|c|c|c|c|c|c|c|c|}
\hline Time & Voltage (V) & Current (A) & $\begin{array}{c}\text { Apparent } \\
\text { Power (VA) }\end{array}$ & $\begin{array}{c}\text { Real } \\
\text { Power (W) }\end{array}$ & $\begin{array}{c}\text { Reactive } \\
\text { Power (VAr) }\end{array}$ & $\begin{array}{c}\text { Power } \\
\text { Factor }\end{array}$ & Frequency \\
\hline $\begin{array}{c}05.10 .2019 \\
12: 06: 48,80\end{array}$ & 226,98353 & 0,33395 & 75,80167 & 75,49347 & 6,82859 & 0,99593 & 49,94426 \\
\hline $\begin{array}{c}05.10 .2019 \\
12: 07: 13,90\end{array}$ & 226,98421 & 0,33150 & 75,24664 & 75,01415 & 5,91057 & 0,99691 & 49,95765 \\
\hline $\begin{array}{c}05.10 .2019 \\
12: 07: 38,99\end{array}$ & 226,83153 & 0,33016 & 74,89102 & 74,63330 & 6,21554 & 0,99655 & 49,97370 \\
\hline $\begin{array}{c}05.10 .2019 \\
12: 07: 45,20\end{array}$ & 226,83325 & 0,33015 & 74,88899 & 74,63330 & 6,18834 & 0,99658 & 49,97210 \\
\hline
\end{tabular}

The data received instantly in Table 1 has been set to 60 seconds as the recording time to be determined by the user.

Data is written to the report file every 60 seconds. With this writing process, old data cannot be deleted, new data can be overwritten with old data and historical analyzes can be checked. $23 \mathrm{~W}$ energy saving lamp is used as a nonlinear load in the system. Current and voltage waveforms drawn by nonlinear load are given in Fig. 13. The data are taken instantly and in real time. The current signal does not resemble the full sine signal due to the nonlinear load used. The maximum, minimum and RMS values of the signals are shown numerically.

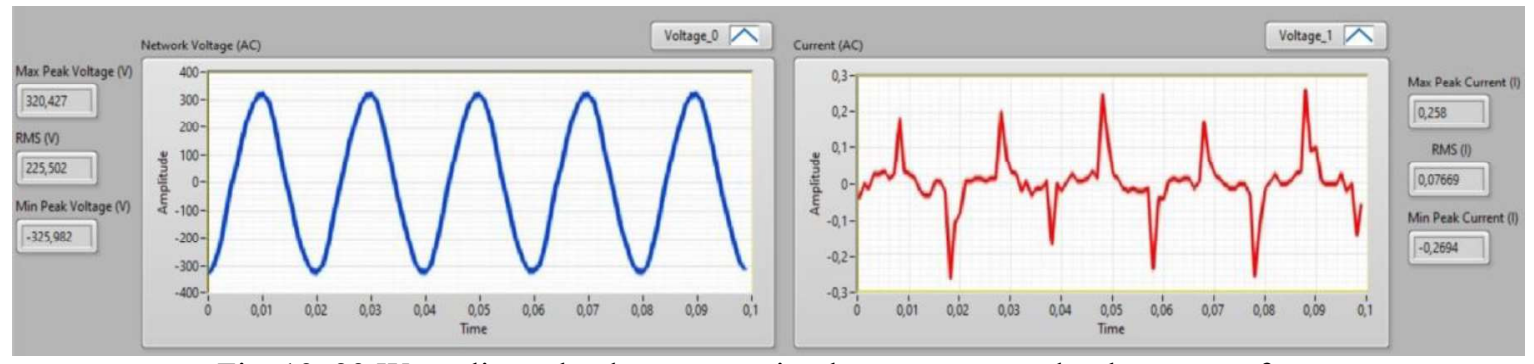

Fig. 13. $23 \mathrm{~W}$ nonlinear load energy saving lamp current and voltage waveforms 
In case of rising / falling voltage and rising current, protection of the loads fed from single phase mains according to the limit values to be determined by the user can be performed automatically or manually in this panel.
In addition, in order to inform the user, failure conditions can be seen from the voltage and current information screen of the system. Instant acquisition of power parameters is shown in Fig. 14.

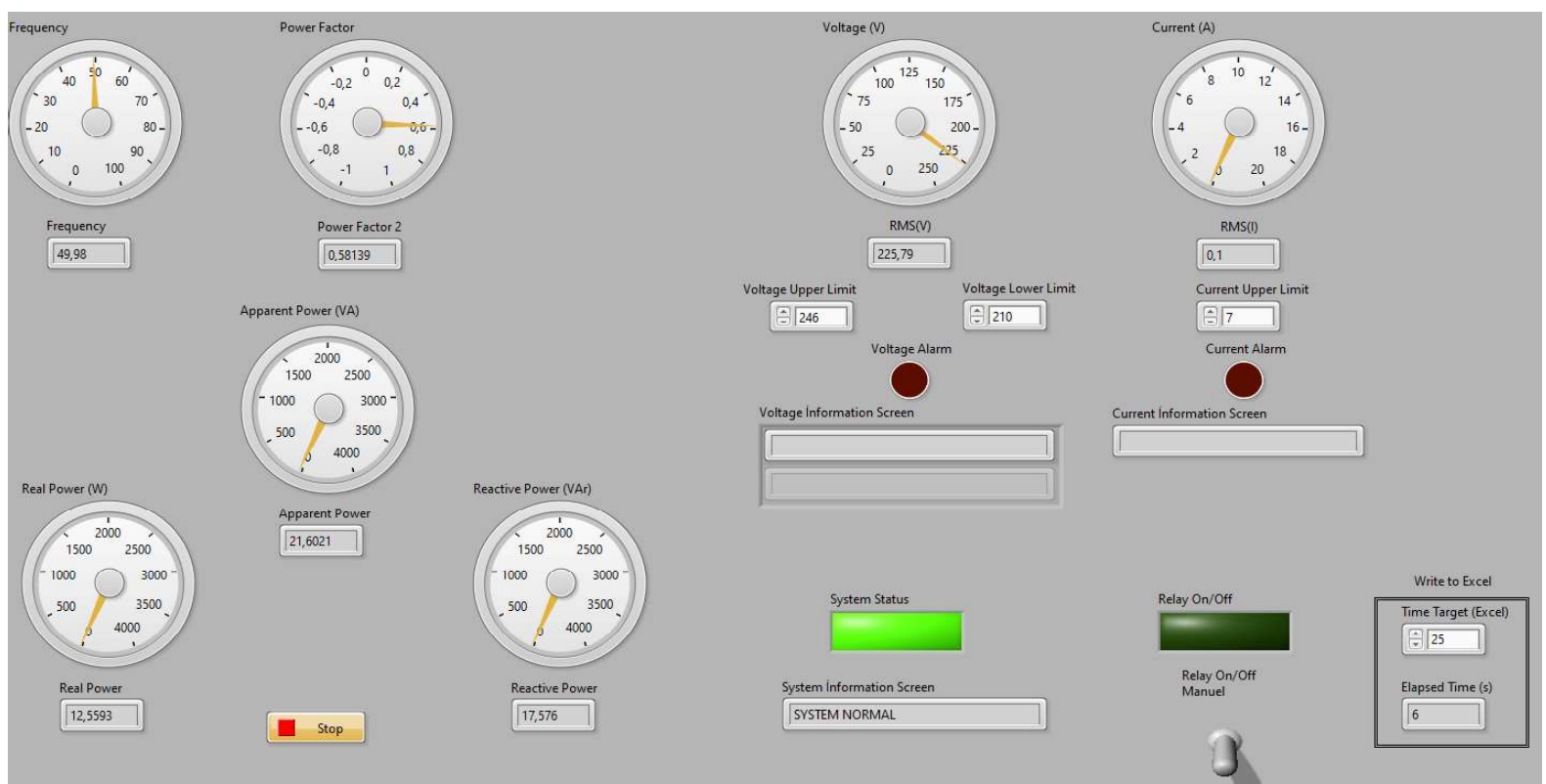

Fig. 14. Nonlinear load power parameters, system status, automatic-manual control and reporting

The instantly received power parameters can record in report file in real time according to a time determined by the user. The power factor was obtained by taking the cosine of the phase difference angle of the current and voltage signals transferred to the graph with 10.000 samples per second with the adjustment made in the
myDAQ card in the LabVIEW program. Apparent power is the total amount of power drawn by the load connected to the system. The product of the apparent power by the cos phi gives the real power in theory. A real time report of $23 \mathrm{~W}$ energy saving lamp is given in Table 2 .

TABLE II

REAL TIME REPORT OF 23 W ENERGY SAVING LAMP

\begin{tabular}{|c|c|c|c|c|c|c|c|}
\hline Time & Voltage (V) & $\begin{array}{c}\text { Current } \\
(\mathrm{A})\end{array}$ & $\begin{array}{c}\text { Apparent } \\
\text { Power (VA) }\end{array}$ & $\begin{array}{c}\text { Real } \\
\text { Power (W) }\end{array}$ & $\begin{array}{c}\text { Reactive } \\
\text { Power (VAr) }\end{array}$ & $\begin{array}{c}\text { Power } \\
\text { Factor }\end{array}$ & Frequency \\
\hline $\begin{array}{c}05.10 .2019 \\
12: 12: 15,55\end{array}$ & 225,87835 & 0,06857 & 15,48848 & 9,11141 & 12,52498 & 0,58827 & 49,96669 \\
\hline $\begin{array}{c}05.10 .2019 \\
12: 12: 40,65\end{array}$ & 225,65836 & 0,10112 & 22,81857 & 12,71314 & 18,94896 & 0,55714 & 49,96709 \\
\hline $\begin{array}{c}05.10 .2019 \\
12: 13: 05,74\end{array}$ & 225,54856 & 0,09032 & 20,37155 & 11,84299 & 16,57538 & 0,58135 & 49,96951 \\
\hline $\begin{array}{c}05.10 .2019 \\
12: 13: 30,84\end{array}$ & 225,33637 & 0,07586 & 17,09402 & 10,09094 & 13,79776 & 0,59032 & 49,97946 \\
\hline
\end{tabular}

The data received instantly in Table 2 is set to 25 seconds as the recording time to be determined by the user. Data is written to the report file every 25 seconds. With this writing process, old data cannot be deleted, new data can be overwritten with old data and historical analyses can be checked. The power factor has been found to be around 0.58 by using a nonlinear load. Linear and nonlinear loads are used together in the residential. Linear loads such as incandescent lamp iron and hair dryer and nonlinear loads such as energy saving lamp and laptop have been used in order to test the proposed system. Current and voltage waveforms of using linear and nonlinear loads are given in Fig.15. As shown in Fig.15 current waveforms is include harmonic. This is due to the nonlinear loads in the system. The real time report of linear and nonlinear loads is given in Table 3. 


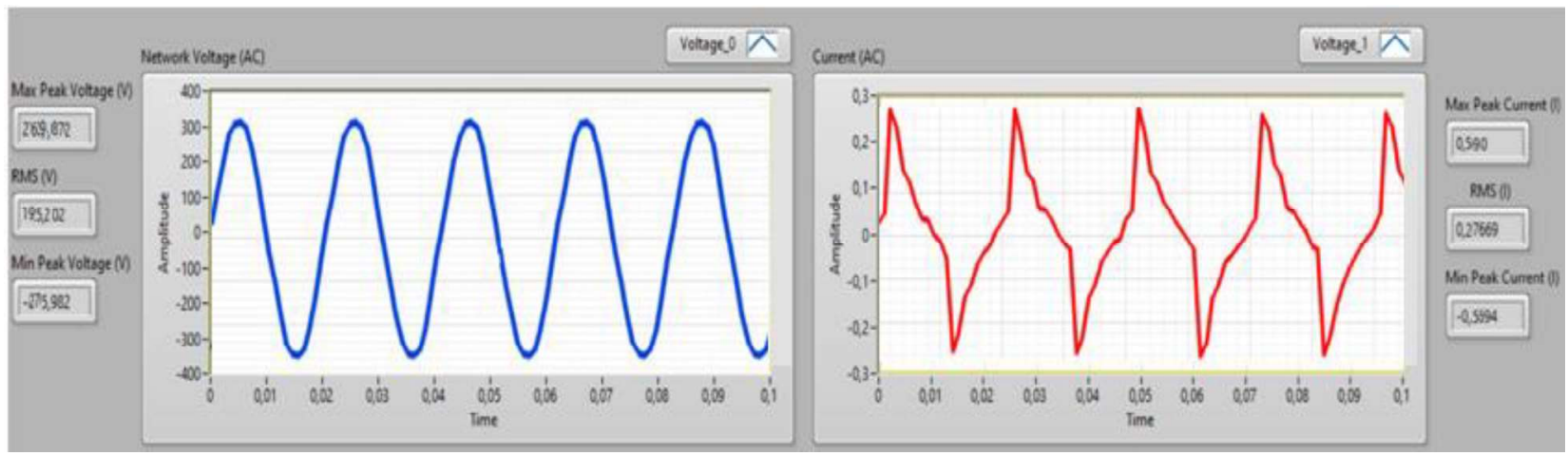

Fig. 15. Voltage and current waveforms of using together linear and nonlinear loads

TABLE III

REAL TIME REPORT OF USING TOGETHER LINEAR AND NONLINEAR LOADS

\begin{tabular}{|c|c|c|c|c|c|c|c|}
\hline Time & Voltage (V) & $\begin{array}{c}\text { Current } \\
(\mathrm{A})\end{array}$ & $\begin{array}{c}\text { Apparent } \\
\text { Power (VA) }\end{array}$ & $\begin{array}{c}\text { Real } \\
\text { Power (W) }\end{array}$ & $\begin{array}{c}\text { Reactive } \\
\text { Power (VAr) }\end{array}$ & $\begin{array}{c}\text { Power } \\
\text { Factor }\end{array}$ & Frequency \\
\hline $\begin{array}{c}18.12 .2019 \\
18: 22: 15,55\end{array}$ & 194,53046 & 0,25016 & 48,66374 & 41,27269 & 25,75886 & 0,84800 & 49,98189 \\
\hline $\begin{array}{c}18.12 .2019 \\
18: 22: 40,65\end{array}$ & 194,05919 & 0,23494 & 45,59227 & 38,63397 & 24,20889 & 0,84738 & 49,97802 \\
\hline $\begin{array}{c}18.12 .2019 \\
18: 23: 05,74\end{array}$ & 194,41001 & 0,25256 & 49,10019 & 41,50341 & 26,23539 & 0,84528 & 49,98101 \\
\hline $\begin{array}{c}18.12 .2019 \\
18: 23: 30,84\end{array}$ & 194,53049 & 0,23315 & 45,35478 & 39,20876 & 22,79758 & 0,86449 & 49,97527 \\
\hline
\end{tabular}

In the proposed system, voltage, current, apparent power, real power, reactive power, power factor and frequency parameters are given in the report. However, if desired, parameters such as apparent energy, active energy, reactive energy, current THD and voltage THD can also be displayed. In addition, the consumed energy can be sent to the consumer as a message. According to this consumption data, the customer can use energy more efficiently by planning energy usage. The system is in a structure that can be developed in line with user requests.

\section{CONCLUSION}

In this study, a real-time system is designed by processing the current and voltage values into the LabVIEW program with myDAQ data acquisition card. In this way, the power parameters of the linear and nonlinear loads used in the residential houses have measured, analyzed and controlled in real time. Real-time monitoring, analysis and control of the consumed energy is important for the efficient use of energy. Thanks to the measured and analyzed power parameters, the consumer energy will be used more carefully. Thus, the energy consumed in the residential will be saved. In addition, energy control can be provided within 4-10 ms to prevent damage to electrical household appliances due to malfunctions in the grid.

In order to the current and voltage information received by the system to be more than the nominal values of the devices, a protection circuit has been made to prevent damage to the devices connected to the system. The protection circuit can be realized both with the interface designed on the computer and with the help of a switch from the outside. In addition, visual and audio alarm circuits have been installed on the computer and test circuit to inform the user of any failure. As a result of the tests, the system worked quickly and accurately. It is possible to make a good energy planning for future times by recording the data in real time and analyzing the historical data. The proposed system can be prefered in residential houses due to the features mentioned below.

It can provide both wired and wireless communication,

The relay used in the system is activated within $4-10 \mathrm{~ms}$ in case of failure. So it is fast in case of failure,

It can be designed according to the user's request,

It can be easily transported and integrated into electrical energy systems more easily,

Performing both energy analysis and protection together,

It is cheaper than energy analyzers that can only measure and monitor without a control mechanism. So it is low cost,

It can be controlled automatically or manually: In case of an error failure in the grid, the energy can be controlled automatically with the LabVIEW program and the used relay. In addition, the energy can be manually controlled with the switch in the system.

Data storage by taking reports and according to these data better energy planning is made; more efficient energy use can be achieved by sharing energy consumption data with the customer.

By using energy monitoring, analysis and control systems, electrical energy is ensured to be efficient, high quality, low cost, uninterrupted and sustainable. Energy management policies can be directed by monitoring the data instantly and recording and reporting power parameters to the database. Energy analysis applications designed according to the user's desire in energy consumption can be tailored according to the 
need. The proposed system can be used not only to monitoring energy, but also to control the energy received or delivered from the system.

\section{REFERENCES}

[1] R. Govindarajan, S. Meikandasivam, and D. Vijayakumar, "Performance Analysis of Smart Energy Monitoring Systems in Realtime", Engineering, Technology \& Applied Science Research, vol. 10. 3, 2020, pp. 5808-5813.

[2] C.T.Yang, S.T. Chen, J.C. Liu, et al." On construction of an energy monitoring service using big data technology for the smart campus". Cluster Computing, vol. 23, 2020, pp.265-288.

[3] M. F. Tuysuz , M. Ucan, R.. Trestian. "A real-time power monitoring and energy-efficient network/interface selection tool for android smartphones". Journal of Network and Computer Application, vol.127, 2019, pp.107-121.

[4] P. A. Kowalska, K. Byrka. "Determinants of the Willingness to Energy Monitoring by Residential Consumers: A Case Study in the City of Wroclaw in Poland". Energies, vol.12.5, 2019,907.

[5] F. Al-Turjman, C. Altrjman, S. Din, A. Paul,. Energy monitoring in IoT-based ad hoc networks: An overview. Computers \& Electrical Engineering, 2019, vol.76, pp.133-142.

[6] M.A. Devlin, B.P. Hayes. "Non-Intrusive Load Monitoring and Classification of Activities of Daily Living using Residential Smart Meter Data". IEEE Transactions on Consumer Electronics,vol 65.3, 2019, pp.339-348.

[7] A.M. Elsayed, M.M.Hegab, S.M. Farrag. "Smart residential load management technique for distribution systems' performance enhancement and consumers' satisfaction achievement". International Transactions on Electrical Energy Systems, vol. 29.4,2019, pp.1-23.

[8] P.K. Neelima, S.Suvarna, M.Roja, D.Madhusudhan. "Smart Energy and Overload Tracking Using Labview". International Journal of Advanced Research in Electrical, Electronics and Instrumentation Engineering, vol.7.6, 2018, pp. 2828-2834.

[9] C. Nutthaka, L. Monthon, B. Suttipong, C. Chow. "Design and Implementation of a smart monitoring system of a modern renewable energy micro-grid system using a low-cost data acquisition system and LabVIEWTM program". Journal of International Council on Electrical Engineering, vol 7.1, 2017,pp. 142-152.

[10] S.S.Mohamed, A.A.Ahmad, A.M. Abdulwadoud, O.E.Mohamed. "Design and Implementation of a Real-Time Smart Home Automation System Based on Arduino Microcontroller Kit and LabVIEW Platform". International Journal of Applied Engineering Research, vol.12.18,2017, pp. 7259-7264.

[11] K.G.Samit, P.B.Natarajan, B.P.Sankata. "Intelligent Smart Home Automation System based on LabVIEW". International Journal of Pure and Applied Mathematics, Vol. 120. 6,2018, pp.339-348.

[12] P. Ali, R.B. Hamid, E.I. Mohamad, B.G. Gevork, J.M. Guerrero. "Real-time simulator and ofine/online closed-loop test bed for power system modeling and development". Electrical Power and Energy Systems, vol.122.106203, 2020, pp.1-16.

[13] K.M.E. Galera, O.E. Llantos. "Mobile Web Energy Monitoring System Using DFRduino Uno". Procedia Computer Science, vol. 124, 2017,706-713.

[14] N. Hnin, Z.M.T. Thaung, M.T. Hla. "Automatic Energy Control And Monitoring System For Building". International Journal of Scientific \& Technology Research, vol. 5.6, 2016, pp.125-129.

[15] R. Govindarajan, S. Meikandasivam, D.Vijayakumar. "Energy Monitoring System Using Zigbee and Arduino". International Journal of Engineering \& Technology Sciences, vol.7.4, 2018, pp.608-611.

[16] S. Sadowski, P. Spachos. "Wireless technologies for smart agricultural monitoring using internet of things devices with energy harvesting capabilities". Computers and Electronics in Agriculture, vol.172.105338, 2020, pp.1-8.

[17] O.S.Shereefdeen, O.O. Kehinde, M.Ismail. "Design and Implementation of Home Appliance Energy Monitoring Device". International Journal of Electrical, Energy and Power System Engineering (IJEEPSE),vol. 2.2,2019, pp. 1-6.

[18] S.K. Omar, K.A. Ahmed. "Real-Time Power Measurements In Smart Building Monitoring System", Journal of University of Duhok (Pure and Eng. Sciences), vol. 20.1, 2017, pp.142-151.

[19] M.M. Jabbar, A. Van den Bossche, C.R. Farhood. "A Smart Voltage and Current Monitoring System for Three Phase Inverters Using an
Android Smartphone Application”. Sensors (Basel), vol.17.4, 2017, pp.2-16.

[20] Fluke: Power Quality, (2020). [Online] Available: https://www.fluke.com/en-us/product/electrical-testing/powerquality/434-435 [Accessed: 2020].

[21] E-commerce: (2020) [Online] Available: https://www.alibaba.com/product-detail/High-quality-HandheldDigital-Energy-

Meter_62315836812.html?spm=a2700.7735675.normalList.97.3bd63 971 atn6Xv\&s=p [Accessed: 2020$]$.

[22] R. Akkan, "Relay Coordination And Selection of Breaker Example of Ihsaniye". Afyon Kocatepe University Graduate School of Natural and Applied Sciences, M.Sc. Thesis, Department of Electrical and Electronics Engineering,2019.

[23] Chint: Brief Katalog [Online] Available: http://www.chint.com.tr/images/content/files/ChintBriefKatalog 2014 .pdf [Accessed: 2020].

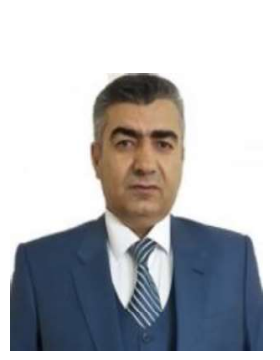

\section{BIOGRAPHIES}

BEHÇET KOCAMAN was born in Bitlis, in 1972. He received the B.S. degree in Electrical Engineering from Yıldız Technical University, (Turkey), in 1993, the M.S. and PhD degrees in Electrical Engineering from Kocaeli University, (Turkey), in 1997 and 2015 respectively. Since 2015 , he has been an Associate Professor with the Electrical and Electronics Engineering department, Bitlis Eren University, (Turkey). His areas of interest include energy efficiency, illumination, renewable energy sourcees, energy management and new transmission and distribution technologies.

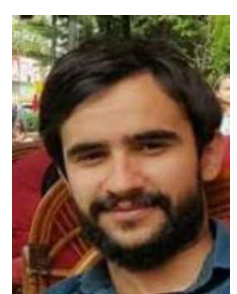

YUNUS YiĞiT was born in Șanlıurfa, in 1993. He received the B.S. degree in Electrical and Electronics Engineering from Sakarya University (Turkey) in 2016. He graudated M.S. degree with the Electrical and Electronics Engineering department, Bitlis Eren University (Turkey) in 2019. 